\title{
Mobile Phones and Economic Sustainability - Perspectives from India
}

\author{
Anirudha Joshi \\ IDC, IIT Bombay \\ Mumbai - 400076 \\ anirudha@iitb.ac.in
}

\begin{abstract}
The last decade has not only been a period of extensive economic growth in India but also a period of optimism about the bottom of the pyramid. Three principles of sustainable economic development have made a big impact on our work: creating the capacity to consume among the people at the bottom of the pyramid, supporting hightech with high-touch to overcome problems of infrastructure and education and rethinking products and services ground up to meet the real needs of the users. Mobile phones have been both a symbol of this recent growth and a partial cause. In our explorations for design of products and systems for sustainable economic development, we have often turned to the mobile phone as a platform of choice. As new technologies such as speech, touch, haptic and gesture interfaces are on the verge of opening opportunities for new designs, it seems to be an opportune time to re-examine these principles and learn lessons from past experiments.
\end{abstract}

Keywords: Mobile phones, interaction design, bottom of the pyramid, economic sustainability.

\section{INTRODUCTION}

In the last decade India has seen a phenomenal growth. Though the year 2008-2009 has been considered a 'slow' year, India still grew at a rate of $6 \%$. This growth has produced (or, perhaps we ought to say, is driven by) a few clear winners. The telecom sector, or more precisely, mobile telephony has been a big growth driver. India had barely 5.5 million phone lines in 1991, compared to 440 million plus mobile phones and 37 million landlines in August 2009 (TRAI, 2009).

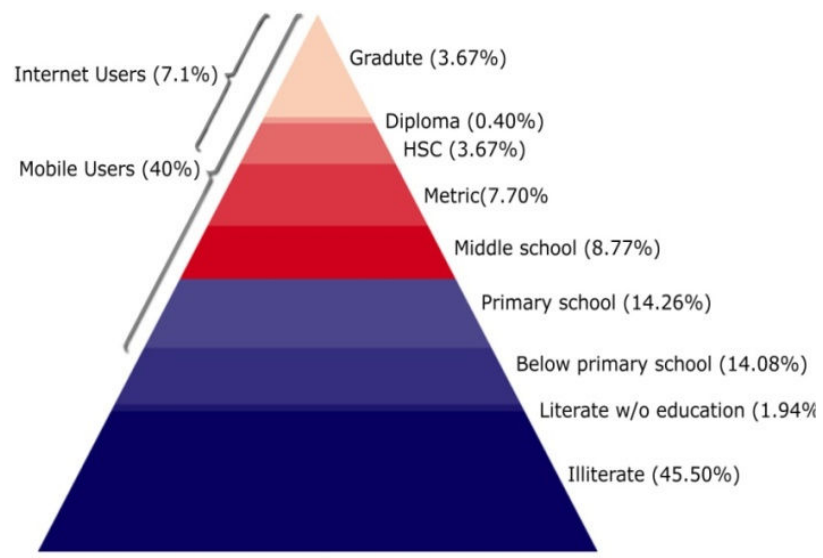

Figure 1: The education in India compared to mobile phone penetration and Internet usage.

Also within the last decade, the idea took root that businesses in general and technology products in particular are not only for the top end of the market, but there could also exists a fortune at the bottom of this pyramid. Prahalad suggests that though charity might feel good, it rarely solves problems in a scalable and sustainable fashion (Prahalad, 2005). By radically changing the way companies do business, it is possible for them to prosper in developing economies and at the same time fight poverty. The fastest growing market today is among the developing countries, but to become successful in these markets, companies need to do two things. Companies need to stop looking at the poor as a 'limited market' and start creating the capacity to consume among them. 
Companies also can't just keep selling products and services that became successful in developed markets, but need to create new products and services that are appropriate for these new markets.

Has there been real growth at the bottom of the pyramid, or has the recent growth been making the rich richer and the poor poorer? Bijapurkar states that when compared on a like-to-like inflation adjusted basis, the total number of households in the lowest two income groups have actually declined sharply between years 1995 and 2006, while the sizes of top three income groups have been growing (Bijapurkar, 2007). She expects that the number of lower income households to continue to decline at $10 \%$ annually.

\section{MOBILE PHONES}

Mobile phones have contributed in a big way in improving efficiency and accessibility of many people. While the growth of mobile telephony seems to be rapid and sustained (the total number of mobile phone subscriptions went up from 415 million in May 2009 to 440 million in July 2009), of particular interest is the spread. Mobile telephony started with the upper strata of society, but it has quickly reached a much larger section of the population. In the last five years, mobile phones have penetrated way beyond the educated, office-going users. A majority of these new mobile phone users are people with limited education and exposure to technology (Figure 1) (Sali, et al., 2009). Taxi drivers, plumbers, carpenters, fishermen, shopkeepers, maids have all taken to benefits of mobile phones. Interestingly, to many of these users, a mobile phone is the only piece of information and communication technology they have ever used.

To borrow the consuming class terms and numbers from (Rao, et al., 1994) and (Bijapurkar, 2007), mobile phones seem to have already covered the 6 million benefit-maximising 'rich' households and the 75 million cost-benefit-optimising 'consuming class' households and are now rapidly moving into the 78 million strong cash-constrained-benefit-seeking 'climbers' households. Further, the growth of mobile phones in urban India seems to have saturated, and most of the new growth seems to be coming from mid-sized towns and villages.

And yet it seems like we are only scratching the surface. The current growth in mobile telephony in India comes from mainly from synchronous voice communication. The full potential of mobile phone as a networked digital device is far from realised. The other typical advantages of information and communication technologies (ICTs) remain unused - even free applications such as the phonebook are used sparingly (Joshi, et al., 2008). In the desktop world, asynchronous communication has played an important role with applications like email, marketing, commerce, learning, government services and social networking. Asynchronous communication in the mobile world at the bottom of the pyramid is largely restricted to missed calls and in very few cases, text messages.

\section{THEMES FOR ECONOMIC SUSTAINABILITY}

In our explorations in interaction design in IDC, IIT Bombay, we have encountered three themes related to economic sustainability of mobile phone designs that echo Prahlad's and Bijapurkar's ideas on economic sustainability of developing markets - creating the capacity to consume, hightech with high-touch and re-thinking ground up. Below, I articulate these themes with traditional examples and summarise examples from our explorations.

\subsection{Creating a Capacity to Consume}

The first theme is related to Prahalad's idea of creating the capacity to consume. The traditional approach to creating capacity to consume among the poor has been to provide products and services for free. This charitable approach may feel good, but it rarely solves the problem in a scalable and sustainable fashion (Prahalad, 2005). A system that makes money by helping the poor make money will emerge as a winning system.

There have been some examples of organisations which do this in India, of which perhaps Amul is the most well-known. Amul started a milk revolution in 1946 by organising milk producers (mostly illiterate women) into hierarchies of cooperatives and marketing the produce as branded, packaged products through retail outlets. In 2005-06, Amul collected 6.3 million litres of milk every day from 2.12 million milk producers in 12,000 villages in Gujarat state and delivered packaged goods worth Rs. 118 million (Chandra, et al., 2007). The "Amul Pattern" has been replicated in many states of India and this has virtually eliminated milk shortages that were common in India till the 1970s, and provided additional income for millions of milk producers.

There have been several other examples. Hindustan Unilever's Shakti project created women entrepreneurs who sell fast moving consumer goods directly to consumers as well as to other 
retailers in nearby villages, thus increasing their household incomes (Prahalad, 2005). Public phones in the early days of the telecom boom provided connectivity and also created employment opportunities. Women's self-help groups enabled banking and financial services access to 55 million members in rural India with outstanding loans of Rs. 197 billion and less than 3\% nonperforming assets in the year 2008 (NABARD, 2008). Their corpus and memberships are rising.

What makes ITC group's e-Chaupal particularly interesting is the use of information and communication technologies such as personal computers and a VSAT terminal. E-Chaupal reduced costs and improved efficiencies and farmer incomes by procuring commodities such as soya directly from farmers and cutting out the middlemen. They also reduced the uncertainty of the profession of agriculture. E-Chaupal manages its operations through a local farmer who is appointed as a sanchalak (administrator) who gets a commission on every transaction. ITC has also been using e-Chaupal as a channel to push sales (Gupta, et al., 2005).

At one level, these organisations can scale up, diversify and improve their efficiency by use of mobile applications. At another level, mobile applications can do the job of aggregating and providing presence in areas where opportunities exist, but such efforts are lacking.

One such application that we worked on is for freelance truck drivers. Road transport in India has more than $70 \%$ share of the goods and freight traffic involving about 5 million truck drivers. Most of these belong to low-income group; have low levels of education and low exposure to technology. Freelance truck drivers own between one to four trucks (usually driven by members of the same family) and they often do not have a scale to run their operation more efficiently or to brand and market themselves. For them, finding a customer becomes a crucial task. The most common way for finding customers for these truck drivers is to wait at a truck stand for a customer to arrive or to call on their phones. We propose a mobile phone application that enables a freelance truck driver operating on long distances to find customers and for customers to find a suitable truck driver (Sali, et al., 2009).

The design of this application has two parts: the truck driver application and the customer application. The customers may download a 'customer application' on their phones or access similar functionality through an interactive voice response system or through the web. Through this application, the customers fire a 'search query' asking for destination, type and weight of goods, date and time and whether the customer needs to hire people to load and unload the goods. A list of search results are returned to the customer which includes information such as name of the truck driver, the type of truck he owns and his rating. From this result, the customer can directly call the truck driver (Figure 2a).
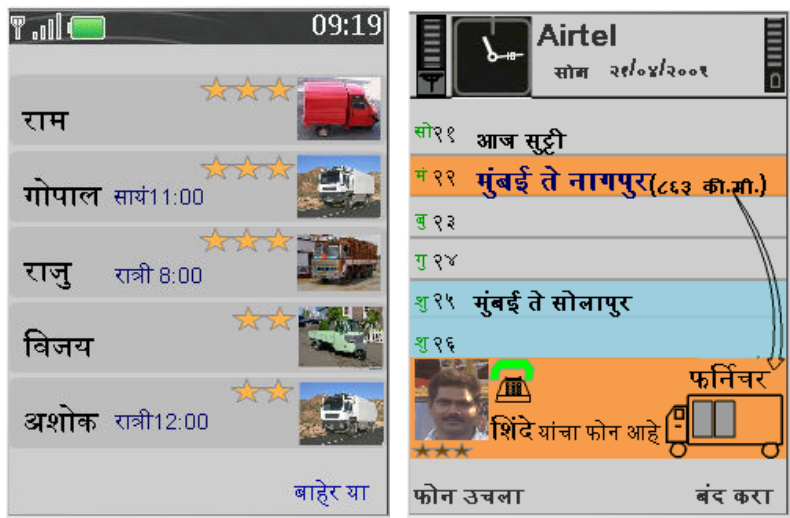

Figure 2: (a) Search results for the customer and (b) truck driver interface before he answers the customers call.

The truck driver has a customised phone with a 'truck driver application' installed. At all times, the desktop screen of the truck driver's phone shows his schedule for 4-5 days. When the truck driver gets a call from a customer through the system, the desktop screen displays details such as the name of the calling customer, his rating, the destination, the distance, the type and weight of the load and the date on which he desires a truck, and whether he needs labour to load and unload the truck (Figure 2b). The truck driver gets this call only if, as per his schedule, he is free on this day and waiting for a customer or if he is carrying a complementary partial load to the same destination 
on the same day. The truck driver can also see his other commitments around this date. Thus, even before the truck driver has answered the phone, he already knows the details of the trip, that he is free in his schedule to make the trip and that the customer is reliable.

The advantages of the system are both ways. It enables truck drivers find new customers and expands and optimises their business. Optimised trucking business and transparency in turn will help reduce costs for customers. The application widens the choice for both truck drivers and customers. Intelligent automated search sets rules that are fair to all drivers. Drivers who have been waiting for a long time, drivers returning from an off day, drivers who are carrying partial loads, and drivers on a return journey to their home towns get priorities in the search list.

\subsection{High-Tech with High-Touch}

The second theme to emerge in our work is the need of high-touch along with high-tech. What we need is a combination of technology, infrastructure and people power. This is a significant departure from the traditional purpose of automation in the western economies, which was to save on manpower costs. In an economy whose demographic dividend of the population is still ahead of us (Nilekani, 2009), automation with the purpose of reducing manpower costs makes little sense. Instead, using the power of people to overcome barriers to technology usage is better.

For example, using the Indian Railways web site to buy tickets would be challenging for a vast majority of Indians - partly because of the usability problems, but also because of limited access to credit cards or online banking. But interestingly, many cyber cafe owners provide this service for a nominal fee - making access to electronic ticketing available to lot more people than would have been otherwise possible (Rangaswamy, 2009).

Another example is SBI Tiny, a project that provides banking services in remote villages too small for banking to otherwise reach, through a local banking facilitator (usually a woman who lives in the same village) (Ramkumar, 2007). SBI Tiny uses off-the-shelf technology products (contactless smart cards for account holders, an Internet and near-field communication enabled mobile phone, a finger print scanner and a receipt printer) integrated through custom software. As a fully automated banking solution, this would have thrown many usability, cost and infrastructure challenges in rural India. But with the human-in-the-loop, these problems are reduced by several orders of magnitude, making rural banking usable and providing employment to boot.

This approach requires not only innovative use of available technologies to reduce costs, it also requires appropriate amount of what Prahalad calls 'deskilling work' (Prahalad, 2005). Work needs to be deskilled so that a cyber cafe operator is able to do the job of a railway reservation clerk or a 10 -th pass village girl is able to perform the role of a banker.

Deskilling is the most obvious in the case study of Aravind Eye Hospitals (AEH) in Tamil Nadu, where a large number of cataract surgeries with intra-ocular lens are performed at a cost starting at Rs. 3,800 (Prahalad, 2005). AEH manages this by hiring unskilled girls, training them extensively in nursing and post-operative patient care and optimally using the doctors' time to perform surgeries. Despite the large scale, the quality of eye care in $\mathrm{AEH}$ is reportedly as good as or better than the best centres for eye care in the world. Similar experiments are being done in the area of healthcare by empowering paramedical workers with ICT tools.

We tried a similar approach towards improving agricultural practices of new polyhouse farmers (Madme, et al., 2009). Modern technique of polyhouse farming promises a better income as compared to traditional farming. For example, a rose farmer can increase his income many fold by managing his production such that he gets maximum number of roses in time for the big day of February $14^{\text {th }}$ (the Valentine's Day). Farmers can also minimise the vagaries of the monsoon or other adverse effects of weather or pest attacks. However the technique requires regular monitoring and control of parameters inside the polyhouse such as temperature, humidity and micronutrients in the soil. With minimal training, uneducated farmers can usually do the manual work of the polyhouse, but they require ongoing expert guidance to interpret and analyse the data and to make course corrections. Our application enables online interaction between farmers and the consultants to enable this. 


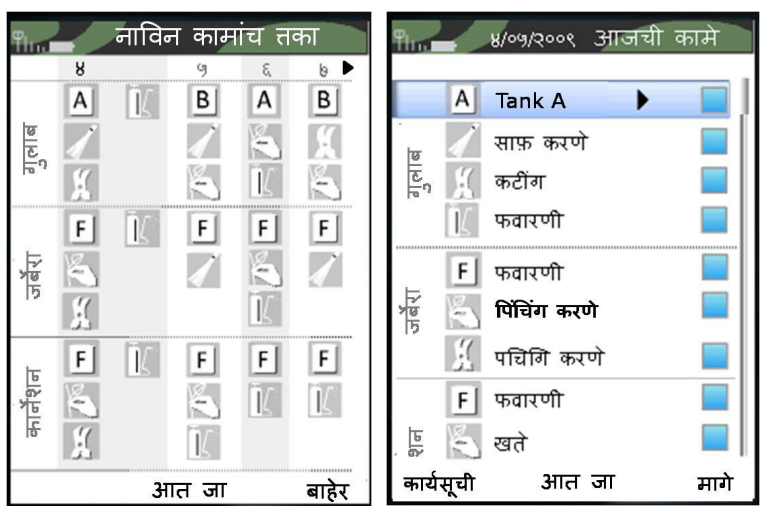

Figure 3: The farmer's interface showing the phone desktop and the detailed schedule.

The interfaces for this application are asymmetric. Consultants are either faculty members in an agricultural university or agricultural graduates living in cities or large towns. They usually have access to an Internet-connected computer and are familiar with English. Therefore the application offers a web-based interface for the consultant on a desktop PC in English. For each farmer the consultant serves, the interface provides a dashboard and enables the consultant to drill-down to the detailed schedules and make changes if necessary.

On the other side, most farmers have access to mobile phones, but no access to computers and little or no knowledge of English. Therefore the application provides a mobile phone based interface in Marathi on desktop of the farmer's phone (Figure 3). The consultant prepares the schedule and sends it to the farmer's mobile phone. The desktop summarises the farmer's schedule for the next two to three days, where each scheduled activity is represented by an icon. The farmer too can drill down to the details of the activities, look up information such as prices and supplier details and report completion of work.

The application enables the uneducated farmer access to recent technology in agriculture and lets him to undertake new activities with minimal risk and low costs. On the other hand, it enables the consultant to provide better services to more farmers, which can in turn bring the cost of hiring a consultant down. Such "high-tech with high-touch" solutions can optimally leverage the benefits of technology and human capabilities and could prove to be an intermediate effective step before fully automated solutions can be deployed.

\subsection{Rethinking Ground Up}

The third theme is the need for rethinking products ground up. Single-serve packaging such as sachets for shampoo and tea made these products accessible by a larger number of people, and also opened new markets for fast-moving consumer goods companies. Nirma, a detergent launched in the mid-80s at one third the price of prevailing prices, out-sold the nearest competitor ten times to one and made available 'adequate quality at affordable prices' (Bijapurkar, 2007). Nokia's 1110 phone, Tata's Rs. 100,000 car Nano and newly launched low-cost netbooks promise to be new examples in this trend.

Exploring the complexities in what she calls "schizophrenic India", Bijapurkar suggests that "the holy grail of the Indian market lies in understanding its plurality" (Bijapurkar, 2007). India is not one monolithic market of a billion people, but a collection of many discrete islands, each with its distinctive economy, consumer character, demography, demand drivers and consumption patterns. To be successful in the Indian market, it is not sufficient to create 'no-frills' cheaper versions of feature-rich expensive products but to invest effort in understanding consumers (and may I add, users) and using that as a starting point to develop appropriate business models (and products). The current experiences have shown that people who don't use ICTs are willing to accept technology and put in the effort to learn to use it. But for the products to become successful, they must be designed to suit the users' real needs.

India presents several obstacles for widespread adoption of information and communication technologies, but perhaps the most persistent problem of all has proved to be the problem of text input in Indian languages. Technology usage in general (including interfaces of consumer goods such as washing machines and television sets) are rarely localised for the Indian markets for the 
same reason. Computer usage in India has been almost entirely in English and is restricted to the English-speaking, upper and upper-middle class people. Mobile phones have recently proved to be an exception to this rule, with a significant number of models becoming available in Indian languages, however text entry in Indian languages continues to be a rare phenomenon.

Whereas many solutions to input text in Indian languages have been available since 1986, none of these have proved to be usable by common users. Current Indian language typing solutions have a steep learning curve. Learning to type requires 30-50 hours of training and practice for a person to reach speeds of 25 words per minute. This is too much of a barrier for ordinary people and only professional typists make this investment. Keylekh is a keyboard that was designed 'ground up' to

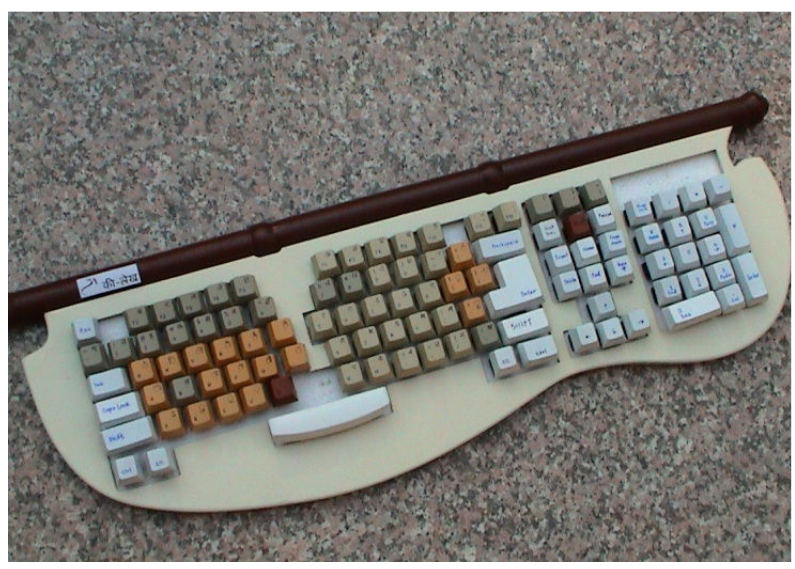

Figure 4: Keylekh, a keyboard based on the structure of the Devanagari script.

attack this problem (Joshi, et al., 2004). Unlike most keyboards available in the market, Keylekh is not based on the hardware dictated by the layouts of the QWERTY keyboards, but by the Varnamala - the fundamental structure of the Devanagari script (Figure 4). The consonants and semi-vowels on Keylekh are organized exactly as in the layout of Varnamala. The vowels are arranged in a 'visual' order in which they typically appear around the consonant glyphs as vowel modifiers.

Evaluations showed that Keylekh was easy to use and easy to learn. Some first-time users could type with no instructions. Instructions seemed to be easy to remember - users who typed once could spontaneously help others. All users could type with minimal instructions and achieve reasonable speeds with 2-4 hours of practice.

Saral is an on-screen text input system for Devanagari that extends these ideas to a mobile phone (Kumar, et al., 2009). Like Keylekh, it follows the structure of the Devanagari script and provides an easy-to-use interface by grouping consonants, vowels and punctuations according to the Varnamala (Figure 5). The input is either through the five navigation and selection keys of the keypad or through a touch screen. When a consonant is pressed, the vowel group is replaced by a group of corresponding vowel modifiers. Audio feedback and colour coding helps people with poor vision. Usability tests involving users with limited education were done to compare Saral to mobile phones from Nokia, Sony Ericson and Samsung that use three different text input systems in Devanagari. Saral did better than all and had a significantly higher number of words successfully typed per user as well as the number of words typed successfully per user without help from the moderator.

Like in language, it takes significantly different approach to tackle the problems arising out of low or no literacy. Rangoli is a visual phonebook designed for low-literate users (Joshi, et al., 2008). The traditional, alphabetical organization or names in a phonebook on mobile phones is not good enough for low-literate users who either do not know or have forgotten the alphabetical order of any script. During user studies, we looked at how people stored phone numbers and contact information on paper. We found that many people owned a small pocket-sized notepad that they referred to as a 'diary'. Most diaries were not organised alphabetically (even diaries that had alphabetical tabs), but people could easily recall the location where a particular contact was written. Diaries were often personalised and reflected the cultural identity of the owner, in particular religious or national identities. 

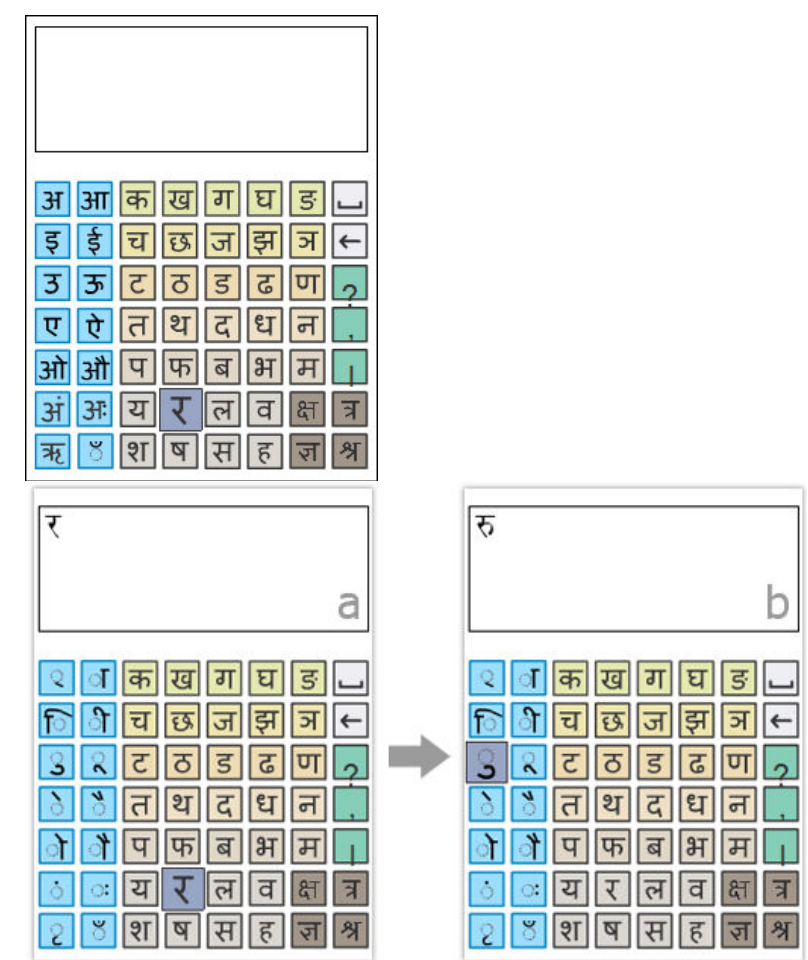

Figure 5: Saral, an on-screen text input system for Devanagari.

Rangoli organizes contacts in nine 'colour pages'. On each colour page, nine icons are displayed in that colour, each of which represents a spatial location where information about a contact could be stored. Thus, a contact in Rangoli is associated with a colour and an icon. When a contact is stored inside the icon, the icon is filled up (Figure 6). Any contact can be accessed by pressing only two strokes on the number-pad - one number associated with a colour, another associated with an icon. The spatial location of each contact does not change even as the phonebook fills up. With practice, the user starts remembering two-digit codes for his frequent contacts and stops using the aid of colours and icons. Rangoli takes away the need to scroll a long list alphabetically. This is
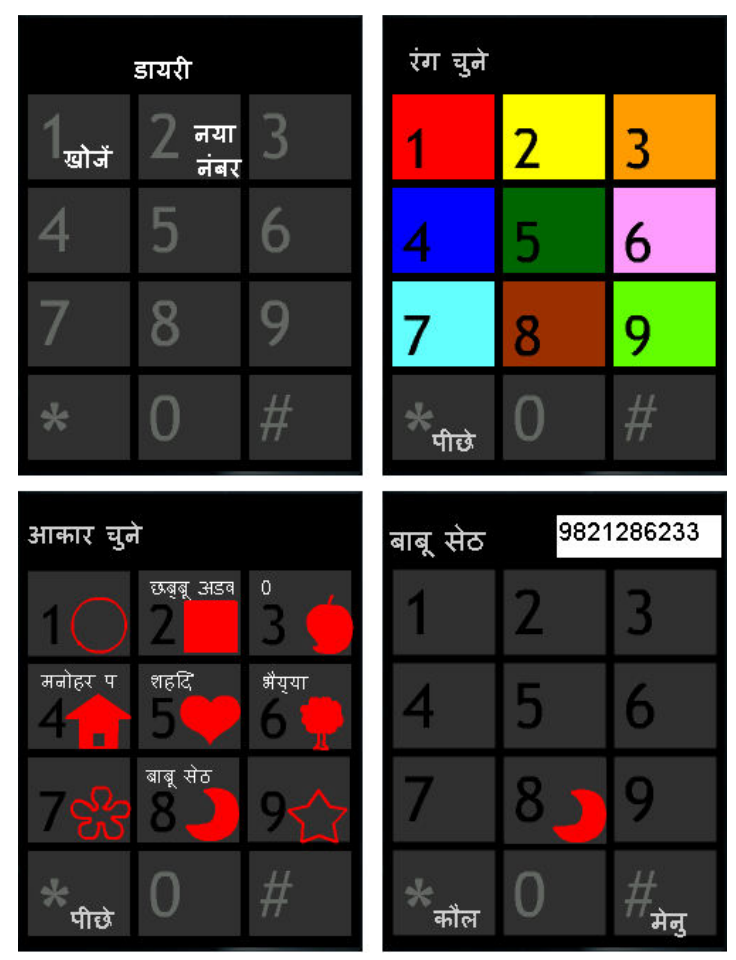

Figure 6: Rangoli, a colours and icons based phonebook. 
useful to users with lower literacy levels, and particularly to those who have difficulties in recalling the alphabetical order and jumping to a desired letter by pressing the keypad key corresponding to that letter. It is also useful in contexts of scripts that have too many letters to be displayed on the number pad.

Evaluations showed that Rangoli reduced number of keystrokes and the amount of time required to look up a contact. Those who had lower levels of literacy found Rangoli more useful than those with higher levels of literacy.

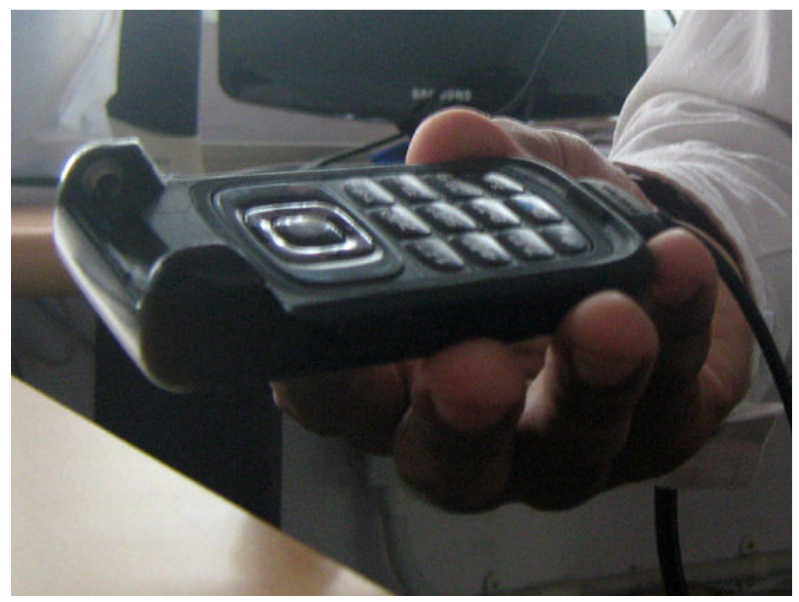

Figure 7: Mobile phone in use without its screen.

A large part of India is not a market filled with users who are craving for the latest gadgets released this season. It is a culture that has learnt to conserve, rather than waste resources. When people invest in a product, they expect it to last for several years (possibly even several generations). It is normal for children to pass on used clothes that they have grown out of to a younger sibling. For a product category that is designed for obsolescence here is an irony - there are many mobile phone repair shops in India. When the battery dies, people prefer to buy another battery than another handset. I met a user whose phone screen came completely unhinged, but he continued using it with a hands-free cable (Figure 7). Mobile phone buy-back schemes are common, and India has a thriving second-hand handset market. New phones need to be designed based on a deep understanding of its users. For example, we could standardise mobile batteries and make them much cheaper. We could extend the life of a phone by making its design modular - so that the user can add hardware later. This will also make it easier to maintain and repair.

\section{CONCLUSIONS}

Now seems to be a good time to relook at the basics in the design of mobile phones and systems surrounding it. A slew of new technologies are on the verge of becoming cheap - speech input and output, touch and gesture input, haptic output, machine translation, semantic web, displays that consumes minimal power and portable image projection. If well integrated, all of these interfaces could be useful in products for the bottom of the pyramid. By becoming the device that harnesses these technologies, the mobile phone has a good chance of providing substantial breakthroughs for many unsolved problems in developing economies like India and becoming a primary computing device for a majority of the world's population, a position that personal computers have enjoyed for the past 20 years.

\section{Acknowledgments}

I thank Nokia and Media Labs Asia for their sponsorships for many projects presented in this paper. I thank the students, researchers and participants in these projects. I also thank the reviewers for their insightful comments during the review that helped me improve this paper. 


\section{REFERENCES}

1. Bijapurkar Rama We are like that only [Book]. - [s.I.] : Penguin Books India, 2007.

2. Chandra Pankaj and Jain Namit The Logistics Sector in India: Overview and Challenges [Online]. - IIM Ahmedabad, 7 March 2007. - 8 September 2009. http://www.iimahd.ernet.in/publications/data/2007-03-07Pankajchandra.pdf.

3. Gupta Indrajit and Rajshekhar M. ITC vs. HLL [Article] // Business World. - 2005. - 5.

4. Joshi Anirudha [et al.] Keylekh: A Keyboard for Text Entry in Indic Scripts [Conference] // CHI 2004. - Vienna : [s.n.], 2004.

5. Joshi Anirudha [et al.] Rangoli: A Visual Phonebook for Low-literate Users [Conference] // Mobile $\mathrm{HCl}$ 2008. - 2008.

6. Kumar Anshuman [et al.] Saral: Devanagari Text input system in Mobile phones [Conference]. - [s.I.] : Globi-Comp - Taking Ubicomp Beyond Developed Worlds, Ubicomp 2009, 2009.

7. Madme Neha and Joshi Anirudha System for Polyhouse Farmers and Consultants [Conference] // USID 2009. - Bangalore : [s.n.], 2009.

8. NABARD Microfinance in India 2007-2008 [Online]. - 2008. http://www.nabard.org/microfinance/shglinkageprogress.asp.

9. Nilekani Nandan Imagining India: Ideas For The New Century [Book]. - [s.I.] : Allen Lane, 2009.

10. Prahalad C.K. The Fortune at the Bottom of the Pyramid [Book]. - [s.I.] : Pearson Education , 2005.

11. Ramkumar V. Fiancial Inculsion and Financial Literacy: SBI Initiatives [Article] // CAB Calling. - 2007. - 3.

12. Rangaswamy Nimmi Keywords in Communication: Mesh-economy and business channels in an Indian urban slum [Conference] // ICA pre-conference on India and Communication Studies. - Chicago : [s.n.], 2009.

13. Rao S.L. and Natarajan I. Indian Market Demographics: The Consumer Classes [Book]. [s.l.] : Global Business Press, 1994.

14. Sali Shweta and Joshi Anirudha Application for Freelance Truck Drivers in India [Conference]. - [s.I.] : Globi-Comp - Taking Ubicomp Beyond Developed Worlds, Ubicomp 2009, 2009.

15. TRAI Telecom Regulatory Authority Of India - Press Release No 64/2009 [Online]. - 20 August 2009. - 8 September 2009. http://www.trai.gov.in/WriteReadData/trai/upload/PressReleases/697/pr20aug09no64.pdf 